\title{
A measure of ionospheric irregularities: zonal velocity and its implications for L-band scintillation at low-latitudes
}

\author{
Claudio Cesaroni ${ }^{*}$, Luca Spogli ${ }^{1,2}$, Giorgiana De Franceschi ${ }^{1}$, Juliana Garrido Damaceno ${ }^{1}$, Marcin Grzesiak ${ }^{3}$,

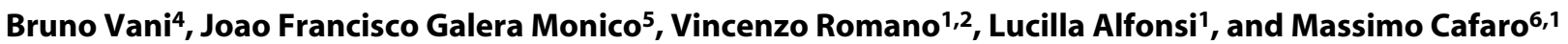 \\ ${ }^{1}$ Istituto Nazionale di Geofisica e Vulcanologia, Italy; \\ 2SpacEarth Technology, Italy; \\ ${ }^{3}$ Space Research Centre of the Polish Academy of Sciences, Poland; \\ ${ }^{4}$ Instituto Federal de Educação, Ciência e Tecnologia de São Paulo, Brazil; \\ 5Universidade Estadual Paulista "Júlio de Mesquita Filho", Brazil; \\ ${ }^{6}$ University of Salento, Italy
}

Key Points:

- We estimated zonal drift velocity of small-scale ionospheric irregularities by means of spaced GNSS receivers technique in Brazil.

- We validated our results against independent measurements and an empirical model.

- We found a very good correlation between zonal drift velocy of the small-scale irregularities and amplitude scintillation occurrence during post-sunset hours.

Citation: Cesaroni, C., Spogli, L., Franceschi, G. D., Damaceno, J. G., Grzesiak, M., Vani, B., Monico, J. F. G., Romano, V., Alfonsi L., and Cafaro, M. (2021). A measure of ionospheric irregularities: zonal velocity and its implications for L-band scintillation at low-latitudes. Earth Planet. Phys., 5(5), 450-461. http://doi.org/10.26464/epp2021042

\begin{abstract}
We estimate the zonal drift velocity of small-scale ionospheric irregularities at low latitude by leveraging the spaced-receivers technique applied to two GNSS receivers for scintillation monitoring installed along the magnetic parallel passing in Presidente Prudente (Brazil, magnetic latitude $12.8^{\circ} \mathrm{S}$ ). The investigated ionospheric sector is ideal to study small-scale irregularities, being located close to the expected position of the southern crest of the equatorial ionospheric anomaly. The measurement campaign took place between September 2013 and February 2014, i.e. equinox and summer solstice seasons under solar maximum, during which the probability of formation of small-scale irregularities is expected to maximize. We found that the hourly average of the velocity increases up to $135 \mathrm{~m} / \mathrm{s}$ right after the local sunset at ionospheric altitudes and then smoothly decreases in the next hours. Such measurements are in agreement with independent estimations of the velocity made by the Incoherent Scatter Radar located at the Jicamarca Radio Observatory (magnetic latitude $0.1^{\circ} \mathrm{N}$ ), by the Boa Vista lonosonde (magnetic latitude $12.0^{\circ} \mathrm{N}$ ), and by applying a recently-developed empirical regional short-term forecasting model. Additionally, we investigated the relationship with the percentage occurrence of amplitude scintillation; we report that it is exponentially dependent on the zonal velocity of the irregularities that cause it.
\end{abstract}

Keywords: ionospheric irregularities; GNSS; scintillation; plasma drift velocity; low-latitude ionosphere; spaced receivers; Equatorial Plasma Bubbles

\section{Introduction}

A deep understanding of the ionospheric phenomena affecting the Global Navigation Satellite System (GNSS) signals propagation benefits from analysis of the dynamics of ionospheric plasma density irregularities. In fact, GNSS signals are affected not only by the phase advance and group delay induced by the presence of the ionosphere, but also by amplitude fluctuations due to diffraction effects, i.e. scintillations (see Ghobadi et al., 2020 and references therein), that are caused by "small-scale" irregularities,

Correspondence to: C. Cesaroni, claudio.cesaroni@ingv.it

Received 17 FEB 2021; Accepted 13 JUL 2021.

Accepted article online 30 JUL 2021.

(C) 2021 by Earth and Planetary Physics. those whose sizes are below the Fresnel's scale (hundreds of meters for L-band signals). lonospheric refraction and diffraction effects can threaten GNSS-based applications, leading, for example, to a degradation of the positioning accuracy (see, e.g., Park et al., 2016; Morton et al., 2020).

At low latitudes, the main cause of the formation of small-scale irregularities is the evolution of Equatorial Plasma Bubbles (EPBs), which are generated primarily by generalized Rayleigh-Taylor (R-T) instability processes (see, e.g., Woodman and La Hoz, 1976; Yokoyama et al., 2014). The principal (but not unique) source of seeding of EPBs is the Pre-Reversal Enhancement (PRE), a strengthening of the eastward electric field at the local sunset that boosts the uplift of the ionospheric F-layer following the increased $E$ x B intensity (see, e.g., Fejer, 2011; Balan et al., 2018 and 
references therein). The probability of EPB occurrence generally increases with PRE strength (Huang CS and Hairston, 2015; Olla et al., 2020). Several issues are still open for the modelling of EPBs formation and dynamics, which translate into challenges for the scintillation mitigation on GNSS signals, such as the relative importance of driving forces, local seeding on the day-to-day variability of EPB occurrence, and storm-time disturbances (see Li GZ et al., 2020 and references therein). The EPBs usually drift eastward in nighttime, cover distances up to one thousand kilometers (see e.g., Bhattacharyya et al., 2001) and are expected to be observed in correspondence with the location of the crests of the Equatorial Ionization Anomaly (EIA, see e.g. Cesaroni et al., 2015).

To study the velocity of the small-scale irregularities embedded in EPBs, we have applied the spaced-receivers technique to six months (September 2013 to February 2014) of GNSS data sampled at $50 \mathrm{~Hz}$ and acquired in Presidente Prudente (São Paulo state, Brazil). Presidente Prudente $\left(22.12^{\circ} \mathrm{S}, 51.41^{\circ} \mathrm{W}\right.$, magnetic latitude $12.8^{\circ} \mathrm{S}$ ) is in a privileged position to investigate small-scale irregularities and their effects on GNSS (see e.g., Sreeja et al., 2011; Spogli et al., 2013b; Cesaroni et al., 2015; Linty et al., 2018; Veettil et al., 2020), since, under solstice and summer equinoctial seasons and high solar flux conditions, it is located below the expected position of the southern crest of EIA.

The spaced-receivers technique has been used for decades to estimate movement of scintillation patterns at the receivers, as well as to estimate the geometric properties of ionospheric plasma irregularities (Basu et al., 1996; Kil et al., 2000; De Paula et al, 2002; Ledvina et al., 2004; Otsuka et al., 2006; Muella et al., 2008, 2014, 2017). The technique is based on transmission of one or more radio waves from a remote source, i.e. an artificial satellite (in our case, a GNSS satellite). If the frequency of the radio waves is greater than the ionospheric plasma frequency (or the electron gyrofrequency), the waves can be diffracted by ionospheric irregularities smaller than the appropriate first Fresnel zone size $\approx 250 \mathrm{~m}$ for the GPS-L1 frequency). The diffraction effects are visible in the signal recorded by a receiver at ground as a scintillation pattern in both amplitude and phase (Yeh and Liu CH, 1982). Using crosscorrelation (Costa et al., 1988) or cross-spectral techniques, the velocity of the amplitude scintillation pattern can be evaluated, allowing an estimation of the zonal velocity, shape, and orientation of the irregularities. In this paper, results obtained with the spaced-receivers technique are compared: (i) with similar measurements made by the Incoherent Scatter Radar located at the Jicamarca Radio Observatory (magnetic latitude $0.1^{\circ} \mathrm{N}$ ) and by the Boa Vista lonosonde (magnetic latitude $12.0^{\circ} \mathrm{N}$ ); and (ii) with the plasma velocity field reconstructed by using the empirical forecasting model developed by Grzesiak et al. (2018). Results relevant to the correlation between zonal drift velocity of the irregularities and amplitude scintillation occurrence above the moderateto-strong threshold are also discussed.

Section 1 provides details about the spaced-receivers technique and about the campaign that has been set up in Presidente Prudente to measure the drift velocity. Additionally, the main principles underlying the Grzesiak et al. (2018) short term forecasting model are also recalled, together with some details regarding how it has been used for the purposes of our study. Sec- tion 2 presents results and discussion; conclusions are provided in Section 3.

\section{Data and Methods}

The spaced-receivers technique here applied is able to derive the zonal velocity of small-scale irregularities $\left(V_{\text {ion }}\right)$ as obtained by measuring the velocity $\left(V_{\text {scint }}\right)$ of the amplitude scintillation pattern. The technique is based on the assumption that both the receivers and the source of the radio waves are sufficiently far from the scattering medium (the ionospheric plasma) and that the relative distance between the receivers is of the order of the scalesize of the irregularities that cause diffraction (Huygen-Fresnel diffraction regime). This hypothesis is verified in the case of GNSS signals (emitted at about $20000 \mathrm{~km}$ altitude) received at the ground, by assuming the scattering medium is a single ionospheric layer (located, e.g., at $350 \mathrm{~km}$ ) and by properly spacing the receivers, as in our case. Additionally, the propagation ray-paths are assumed straight and the signal propagation speed (speed of light) is assumed to be much greater than the scintillation pattern velocity, typically of the order of hundreds of meters per second, or the satellite velocity. Furthermore, the scintillation-causing irregularities are assumed to be aligned along the magnetic field lines and moving predominantly in the East-West magnetic direction (Yeh and Liu CH, 1982).

Figure 1 depicts the idea behind the measurement of the velocity of the amplitude scintillation pattern $\left(V_{\text {scint }}\right)$. Two receivers (REC1 and REC2), acquiring GNSS signals at $50 \mathrm{~Hz}$, are assumed to be spaced $\sim 300 \mathrm{~m}$ from each other, i.e. about the Fresnel scale for Lband signals. At a given time $\left(t=t_{1}\right)$, the signal from a given GNSS satellite, moving with velocity $V_{\text {sat, }}$ is acquired by REC2 when crossing the ionospheric small-scale irregularity moving with velocity $V_{\text {ion. }}$. This generates a scintillation pattern in the recorded signal that appears as a fading (see Carrier-to-Noise Power Ratio reported in red in Figure 1a). At a time $t=t_{2}>t_{1}$, the same irregularity has drifted apart and then crosses the line of sight of REC1, generating again a scintillation pattern (Figure 1b). Under the hypothesis that the irregularity's shape and orientation do not change between $t_{1}$ and $t_{2}$, the scintillation patterns recorded by the two receivers are correlated.

Spaced-receivers analysis estimates $V_{\text {scint }}$ by dividing the receivers' separation distance by the scintillation pattern time lag between the two receivers (estimated through a correlation analysis technique). This measurement method is reasonable, as long as it is assumed that the scintillation pattern velocity is constant during the time lag (Kintner et al., 2004).

To enable measurements of the zonal velocity of the small-scale irregularities over Brazil, a six-months measurement campaign was organized between September 2013 and February 2014 in the frame of the CALIBRA (Countering GNSS high Accuracy applications LImitation due to ionospheric disturbance in BRAzil, https://www.gsa.europa.eu/news/fp7-success-story-calibra-demosvalidate-tangible-results) project. The campaign was carried out in Presidente Prudente. Figure 2 shows the location of the 3 Septentrio PolaRxS receivers (Bougard et al., 2011) deployed in Presidente Prudente (PRU1, PRU2 and PRU3) constituting the Mi- 

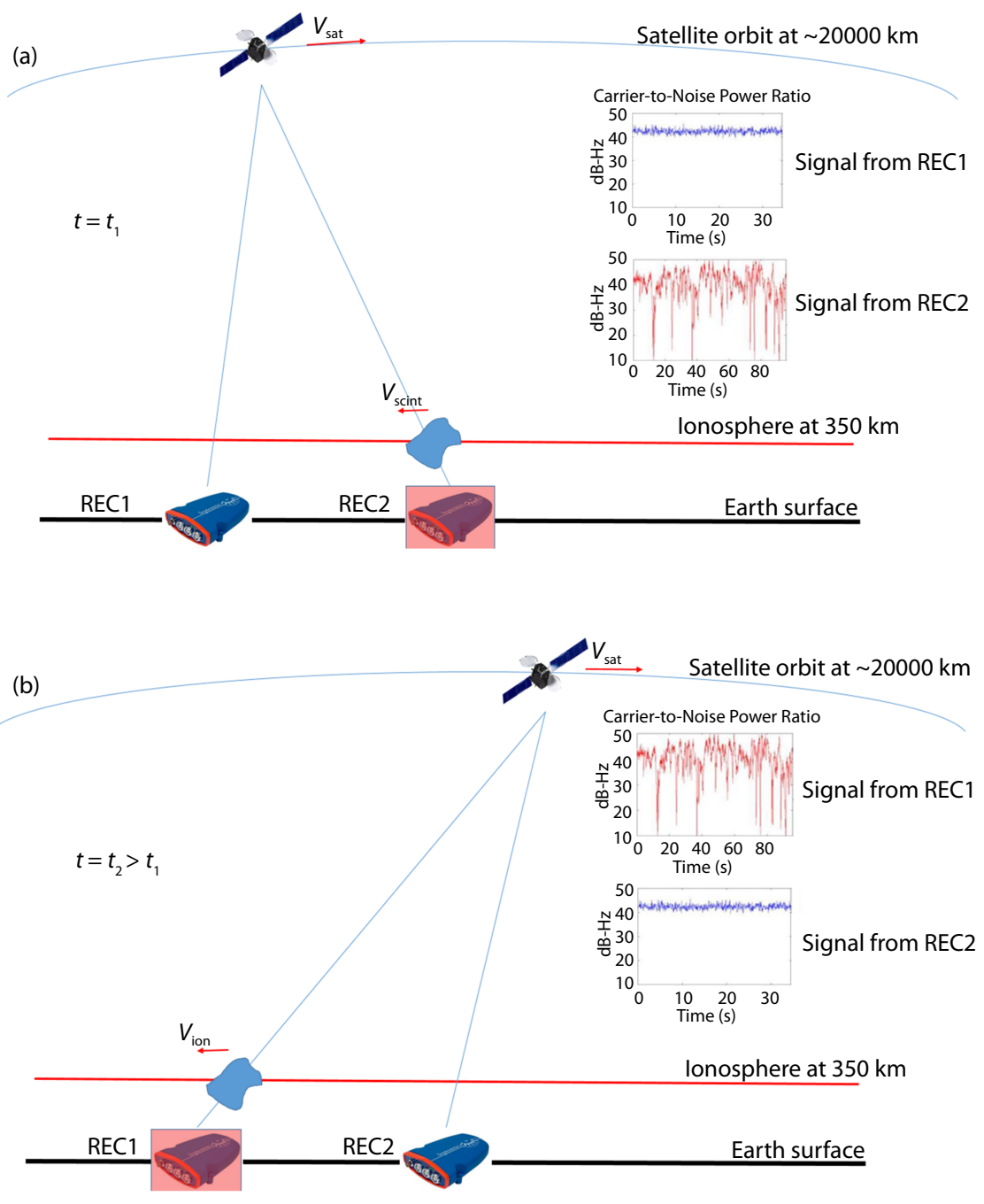

Figure 1. Schematic representation of the measurement of the ionospheric irregularities zonal velocity: the irregularity moves from right to left and encounters first the REC2 receiver (a) and then the REC1 receiver (b). The typical effect induced by the irregularity on the signal is plotted on top right part of both (a) and (b) panels (red curve) in terms of Carrier-to-Noise Power Ratio, while blue curves represent the same quantity under unperturbed conditions.

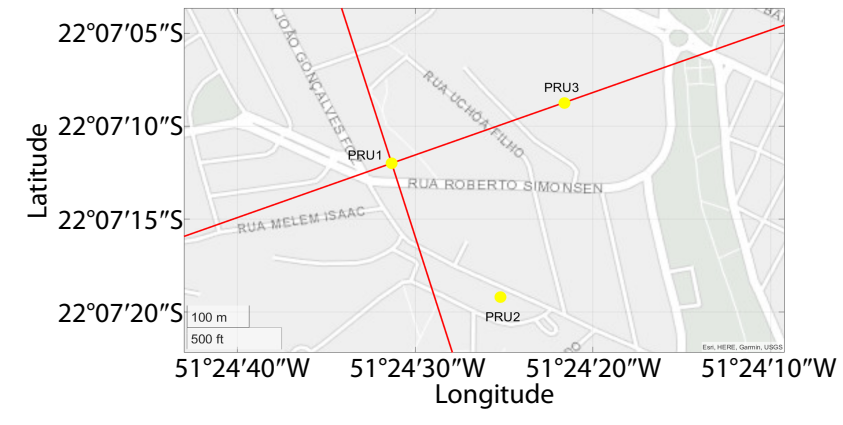

Figure 2. Position of the receivers constituting the Micro Test Area (yellow dots). Red lines indicate the position of the magnetic NorthSouth and East-West directions retrieved by calculatngi the declination angle from IGRF-12 over PRU1.

cro Test Area (MTA), whose coordinates are reported in Table 1. The magnetic declination and inclination of the MTA are $-18.72^{\circ}$ and $-30.54^{\circ}$, respectively. The three receivers were set to acquire data in the interval between 22:00 UT (19:00 LT) and 04:00 UT
Table 1. List of the stations in the Micro Test Area and their geographic coordinates.

\begin{tabular}{ccc}
\hline Station ID & Latitude $\left({ }^{\circ} \mathrm{S}\right)$ & Longitude $\left({ }^{\circ} \mathrm{W}\right)$ \\
\hline PRU 1 & 22.1200455 & 51.4086718 \\
PRU 2 & 22.1220377 & 51.4070793 \\
PRU 3 & 22.1190860 & 51.4060367 \\
\hline
\end{tabular}

(01:00 LT), corresponding to local post-sunset hours, i.e. the hours during which the probability of scintillation occurrence maximizes. It is worth noting here that the MTA (magnetic latitude: $12.8^{\circ} \mathrm{S}$ ) is located very close to the expected position of the southern crest of the EIA, whose position, under high solar flux conditions, is expected between $15^{\circ}$ and $20^{\circ}$ from the magnetic equator (Spogli et al., 2013b; Cesaroni et al., 2015).

Such a privileged position and the fact that the campaign took place under solsticial and summer equinoctial seasons and under high solar flux conditions ensured the largest probability of occurrence of small-scale irregularities in the investigated ionospheric 
sector (Muella et al., 2013, 2014). Moreover, the MTA was located inside the South Atlantic Magnetic Anomaly (SAMA), where the total magnetic field decreases. This region is characterized by a strong longitudinal dependence on low latitude electrodynamics (Abdu et al., 2005; Spogli et al., 2021) and by ionospheric irregularities' formation due to precipitating particles from the near proton belt, which may act as a further source of GNSS signal degradation (see, e.g., Spogli et al., 2013a), including Loss of Lock (Damaceno et al., 2020). Red lines in Figure 2 indicate the approximate position of the magnetic parallel and meridian passing over PRU1 as retrieved by calculating the declination angle from IGRF-12 (Thébault et al., 2015). The PRU1 and PRU3 receivers are located along the magnetic parallel (offset angle is $1.1^{\circ}$ ). In addition they are located $294 \mathrm{~m}$ apart - that is, of the order of the Fresnel's scale of L-band signals. As a consequence, PRU1 and PRU3 were ideally separated to study the zonal velocity, which, as previously mentioned, is predominant with respect to the meridional one (Muella et al., 2014, 2017). The data acquisition during the MTA campaign was almost continuous; few data gaps were encountered, resulting in better than $90 \%$ availability of common days of data.

Considering the geometry of PRU1 and PRU3 receivers, the local magnetic field lines, and the position of the satellites, the equation of the zonal velocity of the ionospheric irregularities is (Ledvina et al., 2004; Muella et al., 2009, 2013):

$$
v_{\text {ion }}=\frac{h_{\text {sat }}-h_{\text {ion }}}{h_{\text {sat }}} v_{\text {scint }}+\frac{h_{\text {ion }}}{h_{\text {sat }}}\left[v_{\text {satx }}+\left(\frac{q_{y}}{q_{x}}\right) v_{\text {satx }}+\left(\frac{q_{z}}{q_{x}}\right) v_{\text {satz }}\right] \text {, }
$$

where $V_{\text {ion }}$ is the zonal velocity of the ionospheric irregularities along the magnetic East-West direction, $V_{\text {scint }}$ is the zonal velocity of the scintillation pattern, and $V_{\text {sat }}$ is the satellite velocity vector, which can be measured by the orbital parameters in the RINEX navigational files. The reference system is the same provided by Ledvina et al. (2004), in which $x$ represents the zonal direction, $y$ is the meridional direction, and $z$ is the vertical direction. The values $h_{\text {sat }}$ and $h_{\text {ion }}$ are the height of the satellites (about $20000 \mathrm{~km}$ ) and the height of the thin ionospheric layer $(350 \mathrm{~km})$, respectively. The satellite velocity vector is projected on the receivers direction assumed to be coincident with the magnetic field reference frame by the factors $\frac{q_{y}}{q_{x}}$ and $\frac{q_{z}}{q_{x}}$. Such factors depend on the satellite's elevation and azimuth angles and on the direction of the magnetic field at the ionospheric pierce point (IPP) (see Appendix A of Ledvina et al., 2004). One way to reduce the unknowns in Equation (1) is to average over several observations, covering different observational geometries, to reduce the impact of the geometry itself and the impact of the vertical velocity of the irregularities, here assumed to be zero. By assuming that the scattering layer is located at $350 \mathrm{~km}$, and by considering observations made at an elevation angle greater than $60^{\circ}$, Equation (1) can be written in the form of Equation (15) of Ledvina et al. (2004), i.e.:

$$
\widehat{V}_{\text {ion }} \sim 0.9828 \cdot \widehat{V}_{\text {scint }}+0.0172 \cdot \widehat{V}_{\text {satx }} \text {, }
$$

in which - indicates the average, as described above. In the remainder of the paper, we identify $V_{\text {ion }}$ with $\hat{V}_{\text {ion }}$.

Figure 3 shows a block diagram of the algorithm to calculate $V_{\text {ion }}$ starting from I and Q, i.e. the post-correlation in-phase and quad- rature components, recorded at $50 \mathrm{~Hz}$ by the Septentrio PolaRxSs in PRU1 and PRU3 (highlighted by a light green shadow in the figure), and from the orbital information in navigational files (highlighted by a grey shadow).

As stated in the introduction, the measure of $V_{\text {scint }}$ is based on the cross-correlation estimation between the signal amplitude recorded by PRU1 and PRU3. By selecting a suitable time window, it is possible to find the optimal correlation lag between the two signals. The selected time window should be the best compromise between avoiding false correlation peaks due to signal noise (too short a time window) and signals de-correlation (too long a time window). For the purpose of this study, the optimal time window is $60 \mathrm{~s}$ (3000 samples). Figure 4 shows an example of cross-correlation versus time lag for satellite $\mathrm{G} 25$ and five different couples of 1-minute data. For each correlation curve, the optimal time lag (peak in the cross-correlation) is detected and then $V_{\text {scint }}$ is determined by applying the following equation:

$$
v_{\text {scint }}=\frac{d_{\text {IPP }}}{t_{\text {lag }}}
$$

where $d_{\mathrm{IPP}}$ is the distance between the two IPPs, one per receiver, of the investigated satellite and $t_{\text {lag }}$ is the optimal time lag, i.e., the one that maximizes the cross correlation.

Thus, by applying this algorithm, $V_{\text {ion }}$ is computed for each minute using the signals simultaneously acquired from each satellite by PRU1 and PRU3 at elevation angles larger than $60^{\circ}$. A threshold is also set on the values of the peak of the cross-correlation. Only correlations with a peak value greater than 0.8 are considered in this work. Correlations with lower peak values could be due to the variability of the shape of the irregularities as they move between receivers, leading to a significant "random" characteristic velocity.

To provide insights into the meaning and usefulness of the method, we performed the following:

(i) comparison with external measurements available in the literature, as the climatological zonal velocity covering by the Jicamarca Incoherent Scatter Radar (as reported by Fejer et al., 2005), and by the ionosonde located in Boa Vista, as provided by the Drift Explorer tool of the Global lonospheric Radio Observatory (GIRO) portal (Reinisch and Galkin, 2011) for the same period as that of the MTA campaign. As discussed in the results, this was performed bearing in mind the different magnetic sectors spanned by the different kinds of measurements and the different wavelengths used to investigate the plasma dynamics;

(ii) comparison with the plasma velocity field reconstructed by using the empirical forecasting model developed by Grzesiak et al. (2018) and further improved by Damaceno et al. (2019). Such a model is based on the transport theory for a scalar field and assumes, for a short time period, a time-independent velocity field. It then relies on the application of the generalized form of the continuity equation to reconstruct the velocity field from Total Electron Content (TEC) measurements (see Equation (1) of Grzesiak et al., 2018) as a first step in the forecasting procedure. The method is based on the discretization of the space in Delauney triangles, whose vertices are at the IPP of the considered ray paths. For the purpose of our study, the model was 


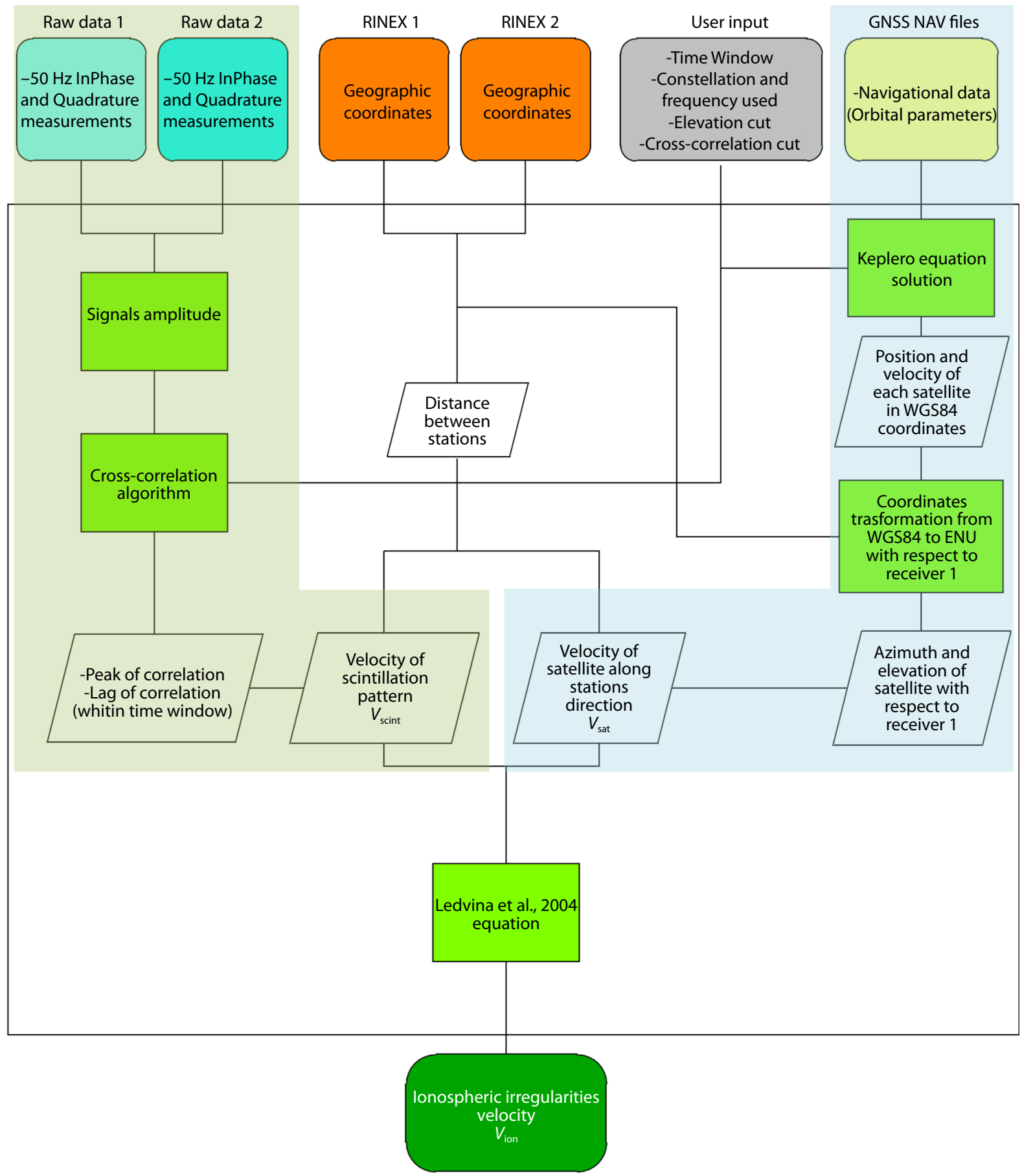

Figure 3. Block diagram of the algorithm for $V_{\text {ion }}$ evaluation. Light green shadow highlights the procedure applied to obtain $V_{\text {scint }}$ and grey shadow covers the procedure for the estimation of $V$.

run for three days (5 to 7 December 2013), featuring the EPB occurrence, by using the RINEX data provided with a 30 seconds rate by the Rede Brasileira de Monitoramento Contínuo (RBMC) network managed by the Instituto Brasileiro de Geografia e Estatística (IBGE, https://www.ibge.gov.br/en/geosciences/geodetic-positioning/geodetic-networks/20079-brazilian-network-for-continuous-monitoring-gnss-systems.html?=\&t=o-que-e). Figure $5 \mathrm{a}$ shows an example of the reconstruction obtained by means of the model of the velocity field from TEC measurements $\left(V_{\text {model }}\right)$ over São Paulo and the corresponding Delauney triangles. The receiv- ers of the RBMC network used to reconstruct the field are reported in Figure 5b. The TEC was retrieved from RINEX data by applying the Gg calibration technique (Ciraolo et al., 2007; Tornatore et al., 2021) and expressed at the IPP considering all GPS satellites in view from the network and the ionosphere as a thin layer at 350 km;

(iii) comparison with amplitude scintillation, in terms of occurrence above the moderate-to-strong scintillation threshold of the amplitude scintillation index S4 measured by the receivers in PRU1, PRU2 and PRU3 during the MTA campaign. Starting from 


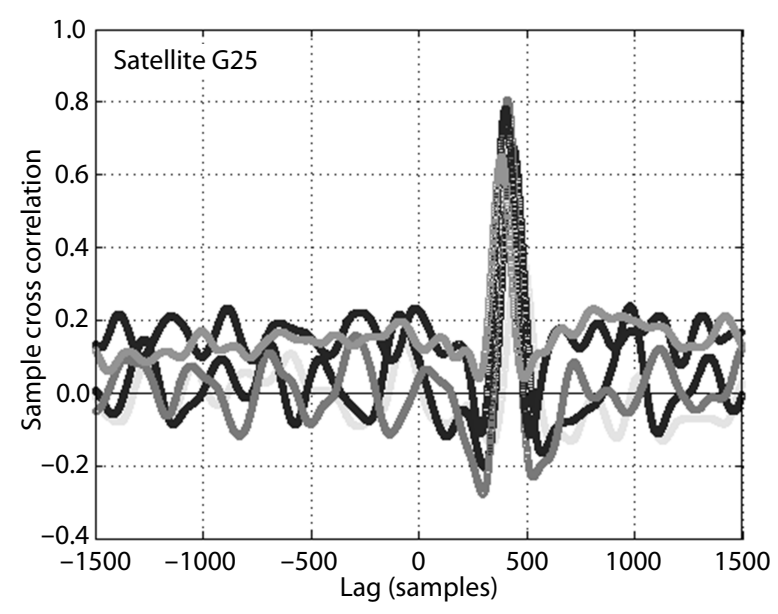

Figure 4. Example of the cross-correlation as a function of the time lag. Each curve represents the cross-correlation for a time window of 1 minute.

the raw amplitude measurements, S4 was provided by each Septentrio PolaRxS receiver for all satellites in view (Bougard et al., 2011) and is defined as the standard deviation of the received power normalized by its mean value (Fremouw et al., 1978). It was calculated on a minute-by-minute basis and corrected to compensate for the thermal noise impact (see Equation (13) of Van Dierendonck et al., 1993). The moderate-to-strong scintillation threshold is usually set as 0.25 (see, e.g., De Franceschi et al., 2019). To calculate the occurrence, the elevation angle threshold was again set to $60^{\circ}$ and the GPS constellation was considered.

\section{Results and Discussion}

The behavior of the hourly averaged $V_{\text {ion }}$ as a function of UT (LT =
UT-3) is provided in the black curve of Figure $6 \mathrm{~b}$. The error bar is the $\pm \sigma$ spread around the mean. The value of $V_{\text {ion }}$ rises meaningfully after 22:00 UT (19:00 LT) and peaks between 23:00 UT and 00:00 UT (corresponding to 20:00 LT and 21:00 LT). At those times, a larger variability with respect to later hours is found in terms of the recorded standard deviation. During the investigated period, the average sunset time $( \pm \sigma)$ at the IPP altitudes over the MTA was 23:26 UT (20:26 LT) ( \pm 21 minutes) range. This variability is related to the larger standard deviation found in the earlier hours. The $V_{\text {ion }}$ enhancement found in correspondence with the bin at 23:00 UT is likely the effect of the PRE, i.e. the increased eastward electric field at the evening terminator that is the main source of EPB seeding (Li GZ et al., 2020). Moreover, as pointed out by Saito et al. (2008), the assumption of negligible meridional drift velocity of the irregularities is valid only if the upward drift velocity is null. This is not satisfied during the early phases of the EPB development (i.e. during PRE), resulting in a larger uncertainty on the zonal velocity of the irregularity.

As mentioned in the previous section, to validate the results, a comparison with the measurements made by the Incoherent Scatter Radar (ISR) located at the Jicamarca Radio Observatory and the drift measurement by the Boa Vista lonosonde was performed and is reported as blue and red curves in Figure $6 \mathrm{~b}$, respectively. To show the different geographic/magnetic sector spanned by the considered instruments, Figure $6 a$ reports their location and the position of the magnetic equator (orange line). The blue curve is obtained from the climatological analysis reported in Fig. 1 of Fejer et al. (2005), in which the authors report the hourly mean of the zonal plasma drift velocity for the previous solar maximum considering different seasonal and solar flux conditions. For our comparison, we selected the curve referring to $F_{10.7}=120 \mathrm{sfu}$ and November-February months (mid-right panel of Fig. 1 in Fejer et
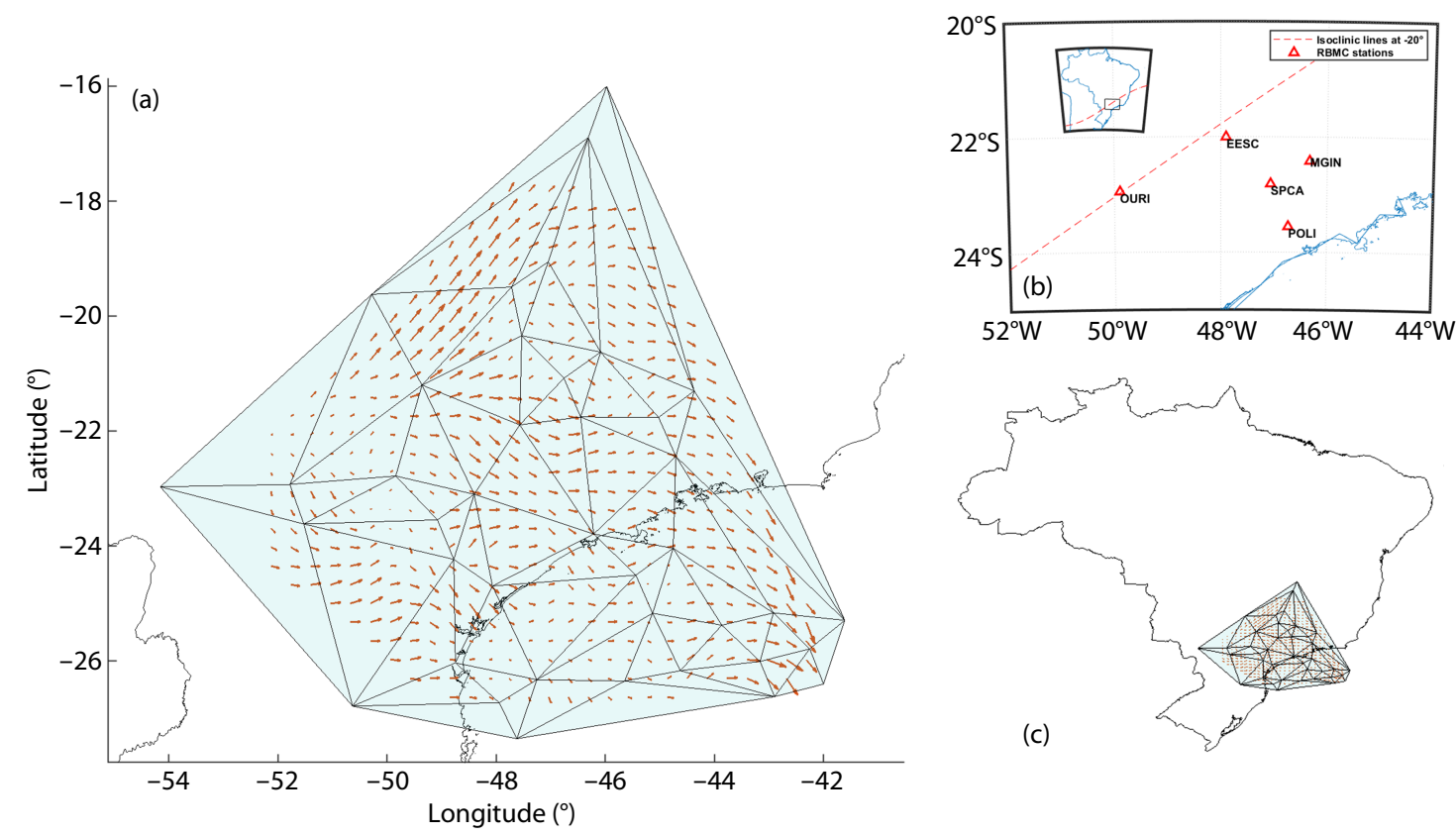

Figure 5. (Panel a) Example of the reconstruction by the forecasting model of the velocity field from TEC measurements $\left(V_{\text {model }}\right)$ over São Paulo and corresponding Delauney triangulation. (Panel b) Location of the stations of the RBMC network used to produce the velocity field and position of the magnetic parallel at $-20^{\circ}$. (Panel c) Zoom out of the plot in Panel a. 

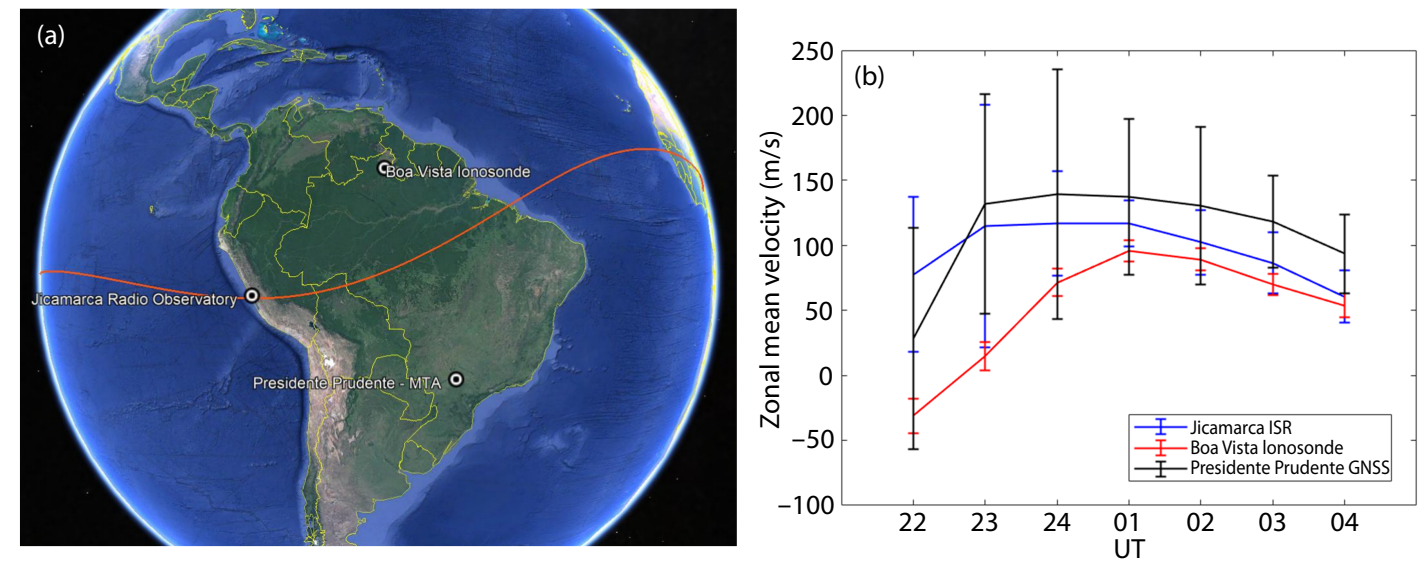

Figure 6. (Panel a) Location of the MTA, of the Jicamarca ISR, and of the Boa Vista lonosonde. Orange line represents the position of the magnetic equator. (Panel b) Hourly mean of the ionospheric irregularities zonal velocity as measured by MTA GNSS receivers (black line, LT = UT-3), by Jicamarca ISR (blue line, LT = UT-5) and Boa Vista lonosonde (red line, LT = UT-4). Error bars represent the $\pm \sigma$ spread around the value.

al., 2005). The red curve is obtained by averaging the hourly values of zonal drift velocity measured in the period September 2013 to February 2014 (same as the MTA campaign) by the Boa Vista ionosonde and available in the GIRO database (Reinisch and Galkin, 2011). Since the data for the ionosondes located close to Presidente Prudente (i.e. Cachoeira Paulista, Campo Grande and Santa Maria) were not able to cover the full period of investigation, Boa Vista ionosonde (magnetic latitude $12^{\circ} \mathrm{N}$ ) was considered to be located at about the magnetic conjugate point of Presidente Prudente (magnetic latitude $12.8^{\circ} \mathrm{S}$ ). Error bars in the figure represent the $\pm \sigma$ spread around the value.

The three measurements of the zonal plasma drift velocity are in agreement, despite some differences that can be noted in the magnitude and peaking time. Two main reasons may account for these differences. On the one hand, the dynamics of the plasma may differ at different locations and in different hemispheres: the ISR is located at the magnetic equator, the ionosonde is in the winter hemisphere and below the northern crest of the Equatorial Ionization Anomaly (EIA), while the GNSS receivers are deployed in the summer hemisphere below the southern crest of the EIA area. On the other hand, the instruments employ different wavelengths and methods to probe the plasma dynamics. Specifically, the Jicamarca ISR observes scatter from irregularities with a scale size of 3 meters, which is half the wavelength. This is the same for incoherent or coherent echoes. Furthermore, Fejer et al. (2005) used a split-beam method with beam separation of 6.8 degrees, which translates into about $40 \mathrm{~km}$ in the $F$ region. Moreover, the ionosonde measures the bottom-side ionosphere, which is known to drift more slowly than the F-layer peak region, where the irregularities measured by GNSS are assumed to be. This justifies the lower values of the velocity measured by the ionosonde (red line in Figure $6 \mathrm{~b}$ ) with respect to the one measured by GNSS and ISR (black and blue lines in Figure 6b, respectively).

In addition, since irregularities with different typical scale sizes are formed in various phases of the Rayleigh-Taylor instability growth and evolution, ISR and GNSS investigate the zonal velocity of irregularities that may form at different times and that may have a relative motion to each other, i.e. different velocities, possibly leading to slightly different magnitudes.

Comparison with the plasma velocity field reconstructed by using the empirical forecasting model developed by Grzesiak et al. (2018) was made by running the model on three days (5 to 7 December 2013), which were characterized by the formation of small-scale irregularities in the post-sunset hours. The results of the comparison are provided in Figure 7, which reports the hourly mean of $V_{\text {ion }}$ provided by the spaced-receivers method as a function of $V_{\text {model}}^{E-W}$, i.e. the magnetic East-West component of the plasma velocity field reconstructed over Presidente Prudente by

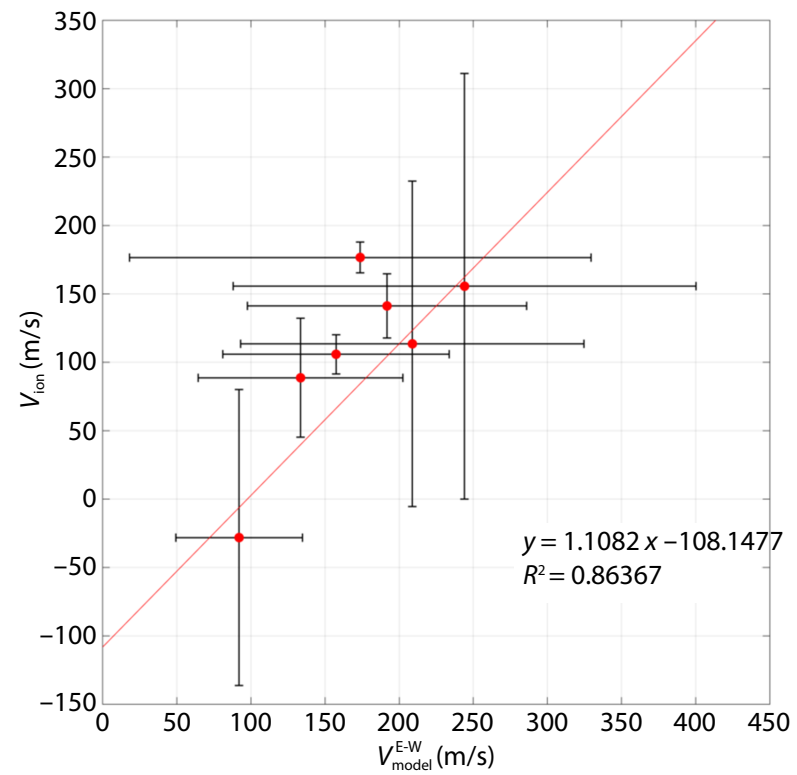

Figure 7. Hourly mean of $V_{\text {ion }}$ provided by the spaced-receivers method as a function of $V_{\text {model, }}^{E-W}$ i.e. the East-West component of the plasma velocity field reconstructed by using the forecasting model developed by Grzesiak et al. (2018). For both quantities, the error bars represent the $\pm \sigma$ spread around the value. Red curve is the linear fit, whose functional form and coefficient of determination $R^{2}$ are also reported. 
using the forecasting model, fed by the calibrated TEC data retrieved from the RBMC receivers in Figure $5 b$. For both quantities, the error bars represent the $\pm \sigma$ spread around the value. The red curve is the linear fit, whose coefficient of determination $R^{2}=$ 0.86367 indicates a good approximation of the regression in deriving $V_{\text {ion }}$ from the $V_{\text {model }}^{E-W}$ measurements. The quality of the regression is further corroborated by the angular coefficient of the fit, which is (with 95\% confidence bounds) $m=1.108(0.602$, $1.614)$, being then compatible with the ideal value of 1 . Additionally, the value of the intercept is $q=-108.1(-205.8,-10.45) \mathrm{m} / \mathrm{s}$, which is not compatible with the ideal value of $0 \mathrm{~m} / \mathrm{s}$. This may be due to biases induced by both the different nature of the two kinds of plasma drift measurement and the fact that $V_{\text {ion }}$ is measured along the magnetic parallel, while $V_{\text {model }}^{E-W}$ is the plasma drift velocity obtained (i) by evaluating the velocity field using measurements covering a broader region than the MTA, and thus featured also by a larger variability of the dip angles, (ii) by projecting the velocity in the magnetic East-West direction and (iii) by interpolating such velocity over Presidente Prudente through the natural neighbors interpolation method (Watson, 1999). Keeping in mind the differences of the two approaches mentioned above, the results in Figure 7 are encouraging, owing to the fact that a quite strong regression's formulation can be used to link the two measurements.

The last step of our analysis concerns the assessment of the relationship between $V_{\text {ion }}$ and the percentage occurrence of amplitude scintillation over the MTA. Figure 8 a shows the hourly occurrence of S4 above 0.25 (blue histogram), usually adopted as a threshold for identifying the moderate to strong scintillation regime (see, e.g. De Franceschi et al., 2019), and the hourly mean of $V_{\text {ion }}$ (black curve) with its $\pm \sigma$ spread around the value as an error bar. The latter is the same curve reported in black in Figure $6 \mathrm{~b}$.

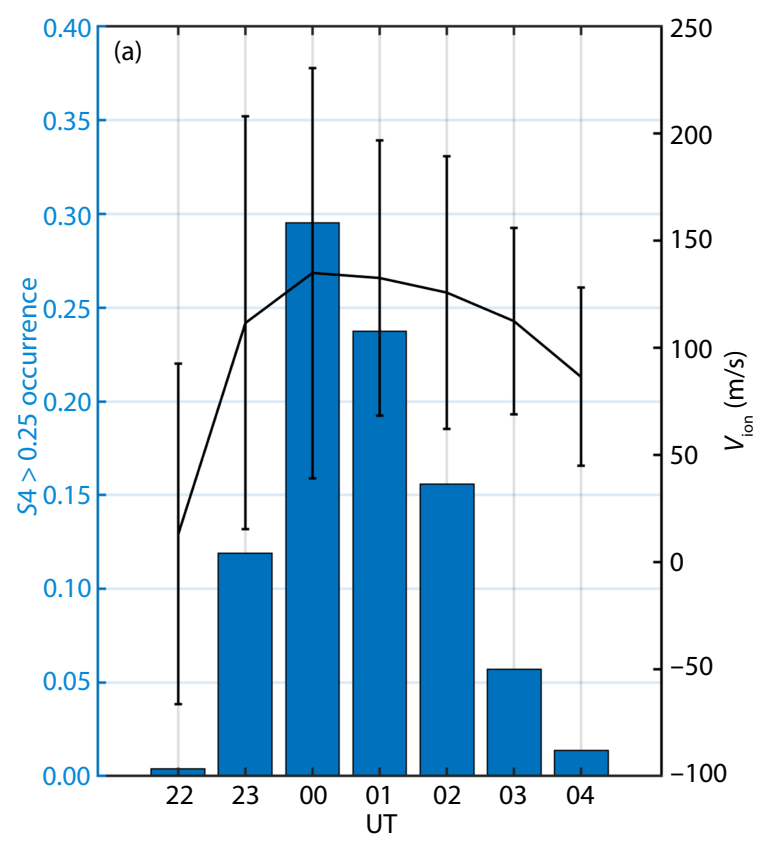

The two quantities behave similarly, rising steeply in the range 22:00 UT to 00:00 UT (19:00 LT to 21:00 LT), reaching maximum scintillation occurrence (at the $30 \%$ level) at 00:00 UT (21:00 LT). Then a slow decrease is found. This behavior is linked to the occurrence of small-scale irregularities embedded in the post-sunset $(\sim 18-24 \mathrm{LT})$ and post-midnight $(\sim 00-06 \mathrm{LT})$ EPBs (Li GZ et al., 2020). The latter induces a lower scintillation occurrence because irregularityt formation is less probable. In fact, small-scale irregularities embedded in post-midnight EPBs have a two-fold nature: they can originate from post-sunset EPBs having long lifetimes or can be freshly generated in the post-midnight hours, especially under low solar flux conditions (see, e.g., Otsuka, 2018), which is not the case of our study. Here we repeat that, despite the fact that both the quantities reported in Figure $8 \mathrm{a}$ are based on the measurements of raw amplitudes from I and Q samples, they are independent. In fact, $V_{\text {ion }}$ is based on a correlation between signals from two receivers while $\mathrm{S} 4$ is a stand-alone measurement from a single receiver. Currently, there is no theoretical relationship justifying the proposition that high values of $\mathrm{S} 4$ come from high values of $V_{\text {ion }}$ and vice-versa. However, a possible explanation of the relationship between the two quantities is that it could be related to the linear growth rate $\gamma$ of the R-T instability, which rules the evolution of the EPBs. This can be expressed as (Sultan, 1996):

$$
\gamma=(1 / L) \frac{\Sigma_{p}^{F}}{\Sigma_{p}^{E}+\Sigma_{p}^{F}}(V-U+g / v)-\beta,
$$

in which $V=(E \times B) / B^{2}$ is the upward vertical plasma drift of the ionospheric F-layer due to the eastward electric field $(\boldsymbol{E}), U$ is the upward neutral wind perpendicular to the magnetic field $(\boldsymbol{B}), g$ is the gravity acceleration constant, $v$ is the ion-neutral collision frequency, $L$ is plasma density gradient scale length, $\beta$ is the recom-

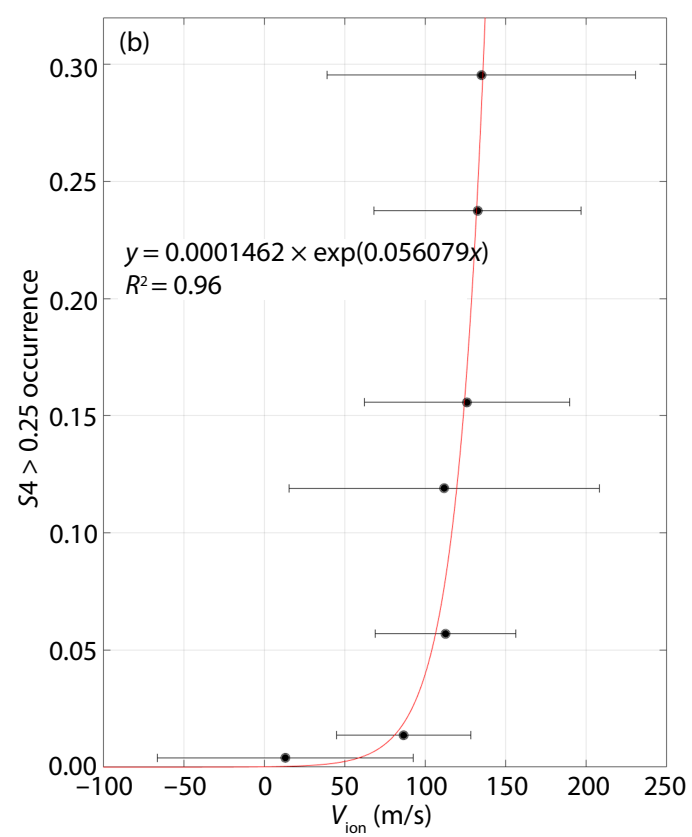

Figure 8. (Panel a) Hourly occurrence of S4 above 0.25 (blue histogram) and hourly mean of $V_{\text {ion }}$ (black curve), from 22 (19) to 04 (01) UT (LT). (Panel b) Hourly occurrence of S4 above 0.25 as a function of $V_{\text {ion. }}$. Red curve is the exponential fit, whose functional form and coefficient of determination $R^{2}$ are also reported. In both panels, the error bars represent the $\pm \sigma$ spread around the value. 
bination rate, while $\Sigma_{p}^{E}$ and $\Sigma_{p}^{F}$ are the E- and F-layers field-line-integrated conductivity.

As the eastward electric $\boldsymbol{E}$ field is the main driver of the zonal plasma motion (Muella et al., 2014), its increase leads to an increase in $V_{\text {ion }}$ and, according to Equation (4), of the growth rate $\gamma$. As a consequence, by assuming that the irregularities inducing amplitude scintillation are due only to the small-scale irregularities triggered by the R-T instability, the larger the $V_{\text {ion, }}$, the larger the occurrence of scintillation.

To further characterize the relationship, Figure $8 b$ reports the $\$ 4$ occurrence above 0.25 as a function of $V_{\text {ion. }}$. The red curve is the exponential fit, whose functional form and coefficient of determination $R^{2}$ are also reported. The qualitative agreement between the two quantities observed in Figure $8 a$ is here provided on a quantitative basis through an empirical formula connecting the two, whose quality is corroborated by a coefficient of determination close to $1\left(R^{2}=0.96\right)$. This relationship highlights the role of ionospheric dynamics in producing scintillations, i.e. the amplitude scintillation intensity is strongly (exponentially) dependent
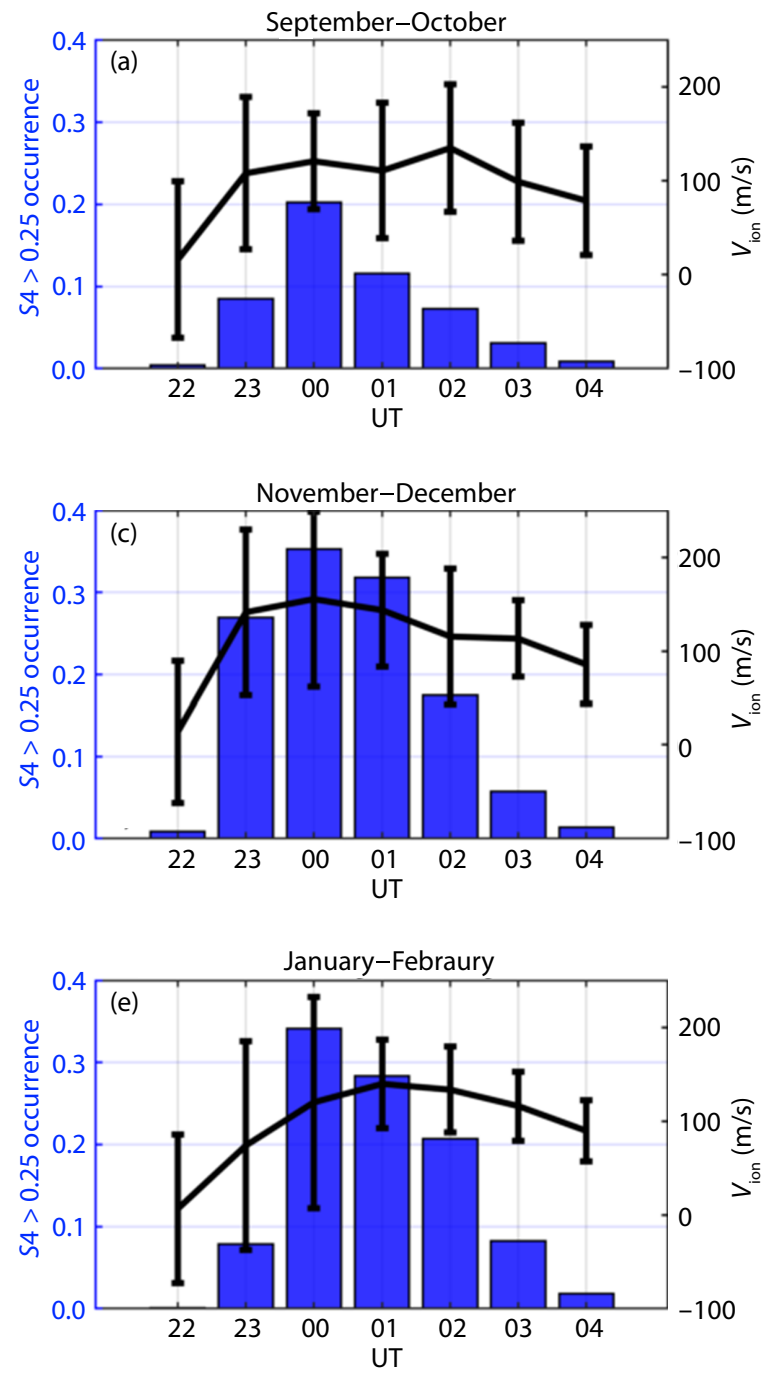

on the zonal velocity of the irregularities causing it.

The relationship between $\mathrm{S} 4$ occurrence and $V_{\text {ion }}$ is further investigated through its dependence on the season. To this aim, Figure 9 reports the same plots of Figure 8, but sorted according to different periods: September-October 2013 (Panels a and b), November-December 2013 (Panels c and d) and January-February 2014 (Panels e and f). The scintillation occurrence is maximal in November-December 2013 and January-December 2014.

The seasonal behavior of S4 is in agreement with previous studies (see, e.g., Muella et al., 2013, 2014; Cesaroni et al., 2015), all of which report a larger occurrence in correspondence with the summer solstice (Panels $c$ and e) than during the equinox (Panel a). Also the zonal wind velocity tends to be larger (and with a larger variability) in correspondence with the summer solstice. This has been identified to be related to increase of the Pedersen conductivity-weighted zonal wind velocity (blowing perpendicular to the magnetic flux tube) (Sobral el al., 2009; Muella et al., 2014).

The seasonal variation of the fit of the $\$ 4$ occurrence above 0.25
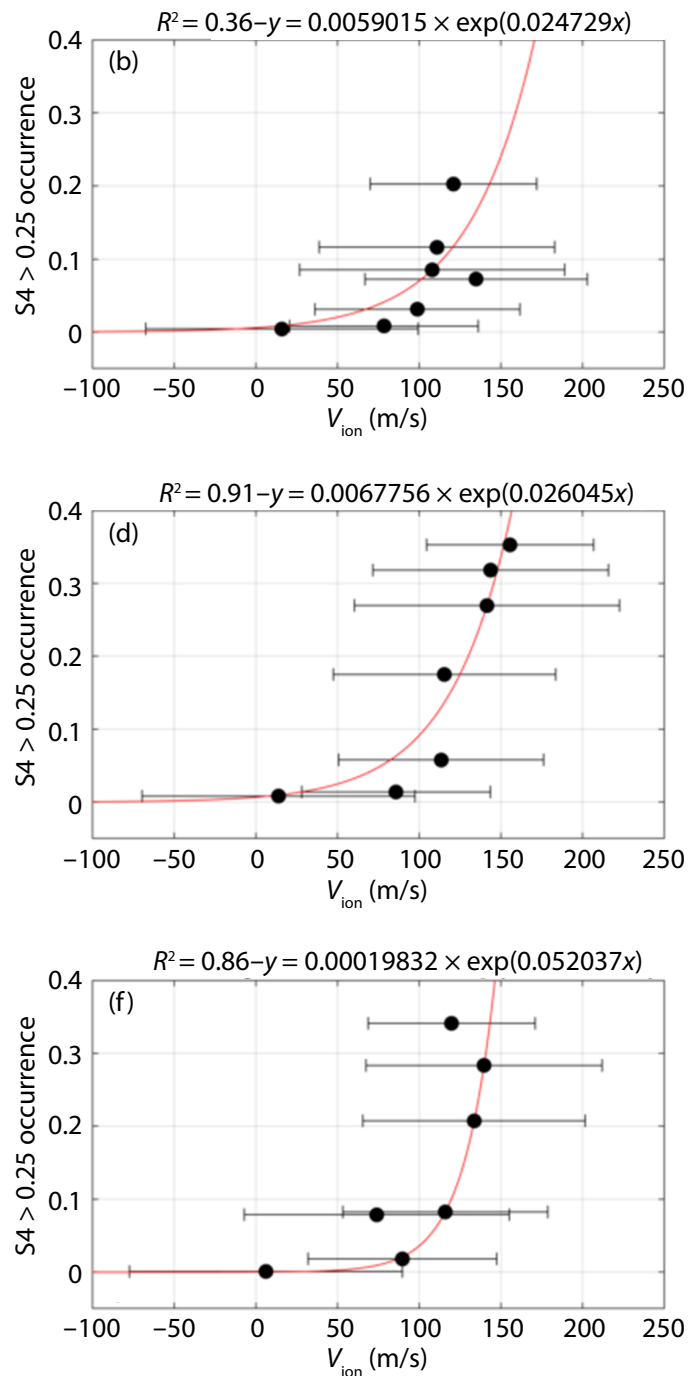

Figure 9. Same plots of Figure 8, but sorted according to different periods: September-October 2013 (Panels a and b), November-December 2013 (Panels c and d) and January-February 2014 (Panels e and f). As in Figure 8, LT = UT-3. 
as a function of $V_{\text {ion }}$ (Figure $9 b-d-f$ ) suggests that for a period with lower scintillation occurrence (such as September-October 2013), the relationship is not well defined (as shown by $R^{2}=0.36$ in Panel b). On the other hand, when the S4 occurrence is larger, the regression is more reliable, even if the coefficients of the fit may vary significantly (Panels $d$ and $f$ ). We checked also if this behavior may be due to different geomagnetic activity conditions, obtaining no significant dependence on that factor (not reported here in order to save space). Also the number of samples used to produce the various plots in Figure 9 is consistent, indicating no meaningful statistical effects in the reported behavior.

\section{Conclusions}

In this paper, we have estimated the zonal velocity of small-scale ionospheric irregularities $\left(V_{\text {ion }}\right)$ by leveraging on the spaced-receiver technique (Ledvina et al., 2004) applied to data from a sixmonths (September 2013 to February 2014) campaign, collected by the receivers constituting a Micro Test Area in Presidente Prudente, Brazil. The MTA (magnetic latitude: $12.8^{\circ} \mathrm{S}$ ) was located in a privileged site, since it was close to the expected position of the southern crest of the EIA and inside the SAMA. The campaign took place under solstice and summer equinoctial seasons and under high solar flux conditions, ensuring the largest probability of occurrence of small-scale irregularities in the investigated ionospheric sector (see, e.g., Muella et al., 2013, 2014).

With respect to the reliability of the technique here adopted to measure $V_{\text {ion, }}$ we warn the reader that it may be biased with respect to the "true" scintillation pattern velocity, because of two different factors:

(1) The scintillation pattern evolves in time as it moves between receivers, so the measured velocity is not the actual velocity of the scintillation pattern. A "random" characteristic velocity due to the changing shape of the pattern perturbs the "true" pattern velocity during the motion between the two receivers. In our experiment, we have assumed that the random velocity can be considered negligible ("frozen-in" hypothesis) since the considered receivers are close enough that we could reasonably consider the shape of the irregularities to be unlikely to change between the two receivers. The typical time lag, in fact, is about a couple of seconds;

(2) The presence of the so-called "windowing effect" in the crosscorrelation. Cross-correlation of two scintillation patterns over a finite interval causes apparent decorrelation. This is because the two scintillation patterns at two spaced receivers for the same finite time span are typically not the same. This effect is particularly evident when (i) the "random" characteristic velocity is not negligible; (ii) the scintillations are weak or (iii) the receivers' noise is significant.

Bearing this in mind, our first result is the dependence of $V_{\text {ion }}$ as a function of the UT hour (LT = UT-3). We report that the hourly average of $V_{\text {ion }}$ in the investigated period steeply increased up to $135 \pm 96 \mathrm{~m} / \mathrm{s}$ right after the local sunset at ionospheric altitudes and then smoothly decreased in the later hours. This is in agreement with the expected behavior due to the effect of the pre-reversal enhancement, which increases the eastward electric field at the evening terminator. This is addressed as the main seed to the formation of plasma bubbles, and as responsible for increasing the R-T growth rate (see Equation (4)), upon which the probability of formation of small-scale irregularities depends. This conclusion is also in agreement with:

(i) The review by Li and co-authors (2020), which reports mean velocities over Sanya (China) during 2011-2013 (high solar activity) as ranging from 145 to $75 \mathrm{~m} / \mathrm{s}$ during the interval 20:00-01:00 LT;

(ii) The work by Saito et al. (2008), which reports a velocity of about $130 \mathrm{~m} / \mathrm{s}$ over Phu Thuy (Vietnam) on March 2007 (low solar activity) at 20:00 LT;

(iii) the work by Muella et al. (2014), which reports a zonal velocity decreasing from $130 \mathrm{~m} / \mathrm{s}$ at 19:30 LT to $110 \mathrm{~m} / \mathrm{s}$ at 02:00 LT over São Luís during the December 2002 (high solar activity);

(iv) the work by Otsuka et al. (2006), which reports (under similar conditions of the previous solar cycle) a zonal velocity that decreases from as high as $150 \mathrm{~m} / \mathrm{s}$ at 20:00 LT down to about $65 \mathrm{~m} / \mathrm{s}$ at 02:00 LT in the Indonesian sector.

Comparisons with measurements made by the Incoherent Scatter Radar located at the Jicamarca Radio Observatory and by the Boa Vista lonosonde are in reasonable agreement, taking into account the different magnetic sectors, scales of the irregularities, and altitudes probed by the different techniques.

From comparison with the plasma velocity field reconstructed by using the empirical forecasting model developed by Grzesiak et al. (2018), we find a reliable $\left(R^{2}=0.9\right)$ linear regression function relating $V_{\text {ion }}$ with the magnetic East-West component of the plasma velocity field reconstructed over Presidente Prudente $\left(V_{\text {model }}^{E-W}\right)$, having the form $V_{\text {ion }}=1.1 V_{\text {model }}^{\mathrm{E}-\mathrm{W}}-108.1 \frac{\mathrm{m}}{\mathrm{s}}$ (see Figure 7).

The assessment of the relationship between $V_{\text {ion }}$ and the percentage occurrence of amplitude scintillation over the MTA (including its seasonal variation) highlights that the scintillation is exponentially dependent on the zonal velocity of the irregularities that cause it. In addition, we found that, the larger the S4 occurrence, the more reliable the exponential regression.

This work paves the way to the use of plasma drift velocity measurements provided by the Grzesiak et al. (2018) model as a means to infer scintillation occurrence. Specifically, in this work we provide empirical formulas of the following kind: $\$ 4$ occurrence $=$ $f\left(V_{\text {ion }}\right)$ and $V_{\text {ion }}=g\left(V_{\text {model }}^{E-W}\right), f$ and $g$ being the functional forms reported in Figure $8 \mathrm{~b}$ and Figure 7 , respectively. We recall here that they have been obtained on a different statistical basis, as $g$ has been evaluated by using just 3 days of model runs, while $f$ has been evaluated by using the full campaign dataset. Our future plan is to assess the feasibility and reliability of retrieving the occurrence of S4 by measuring $V_{\text {model, }}^{\mathrm{E}-\mathrm{W}}$ i.e. by evaluating S4 occurrence $=f\left(g\left(V_{\text {model }}^{\mathrm{E}-\mathrm{W}}\right)\right)$ on a larger statistical basis. The advantage of using the Grzesiak et al. (2018) model to infer S4 occurrence lies in the fact that it is based on measurements provided by a network that is not constrained by being specifically designed for scintillation monitoring and by being deployed along a particular direction and with a fixed spacing. 


\section{Acknowledgments and data}

This Micro Test Area experiment and the development of the Grzesiak et al. (2018) model have been conducted in the frame of the CALIBRA (Countering GNSS high Accuracy applications Limitations due to lonospheric disturbances in BRAzil) project, which was submitted within the call FP7-GALILEO-2011-GSA-1a and GNSS-SP, funded by FAPESP (Process 06/04008-2).

Improvement of the the Grzesiak et al. (2018) model has been realized in the frame of the TREASURE (Training REsearch and Applications Network to Support the Ultimate Real-Time High Accuracy EGNSS Solution) project, which received funding from the European Union's Horizon 2020 research and innovation programme under the Marie Skłodowska-Curie Actions grant agreement No 722023.

The authors would like to thank Instituto Brasileiro de Geografia e Estatística for data from Rede Brasileira de Monitoramento Contínuo dos Sistemas GNSS. The RINEX data are available at geoftp.ibge.gov.br.

The authors would like to thank Lowell Global lonosphere Radio Observatory (GIRO) Data Center for the provision of ionospheric drift data of the Boa Vista lonosonde, available at the DriftBase web portal (https://ulcar.uml.edu/DriftBase/).

Data from the Incoherent Scatter Radar located at the Jicamarca Radio Observatory are those reported in the paper by Fejer et al. (2005), to which the reader is referred to for any further information.

\section{References}

Abdu, M. A., Batista, I. S., Carrasco, A. J., and Brum, C. G. M. (2005). South Atlantic magnetic anomaly ionization: $A$ review and a new focus on electrodynamic effects in the equatorial ionosphere. J. Atmos. Sol.-Terr. Phys., 67(17-18), 1643-1657. https://doi.org/10.1016/j.jastp.2005.01.014

Balan, N., Liu, L. B., and Le, H. J. (2018). A brief review of equatorial ionization anomaly and ionospheric irregularities. Earth Planet. Phys., 2(4), 257-275. https://doi.org/10.26464/epp2018025

Basu, S., Kudeki, E., Basu, S., Valladares, C. E., Weber, E. J., Zengingonul, H. P., Bhattacharyya, S., Sheehan, R., Meriwether, J. W., ... Espinoza, J. (1996). Scintillations, plasma drifts, and neutral winds in the equatorial ionosphere after sunset. J. Geophys. Res. Space Phys., 101(A12), 26795-26809. https://doi.org/10.1029/96JA00760

Bhattacharyya, A., Basu, S., Groves, K. M., Valladares, C. E., and Sheehan, R. (2001). Dynamics of equatorial $F$ region irregularities from spaced receiver scintillation observations. Geophys. Res. Lett., 28(1), 119-122. https://doi.org/10.1029/2000GL012288

Bougard, B., Sleewaegen, J. M., Spogli, L., Veettil, S. V., and Monico, J. F. (2011). CIGALA: Challenging the solar maximum in Brazil with PolaRxS. In Proceedings of the 24th International Technical Meeting of the Satellite Division of the Institute of Navigation (ION GNSS 2011) (pp. 2572-2579). Portland: ION.

Cesaroni, C., Spogli, L., Alfonsi, L., De Franceschi, G., Ciraolo, L., Monico, J. F. G., Scotto, C., Romano, V., Aquino, M., and Bougard, B. (2015). L-band scintillations and calibrated total electron content gradients over Brazil during the last solar maximum. J. Space Wea. Space Climate, 5, A36. https://doi.org/10.1051/swsc/2015038

Ciraolo, L., Azpilicueta, F., Brunini, C., Meza, A., and Radicella, S. M. (2007). Calibration errors on experimental slant total electron content (TEC) determined with GPS. J. Geod., 81(2), 111-120. https://doi.org/10.1007/s00190-006-0093-1

Costa, E., Fougere, P. F., and Basu, S. (1988). Cross-correlation analysis and interpretation of spaced-receiver measurements. Radio Sci., 23(2), 141-162. https://doi.org/10.1029/RS023i002p00141

Damaceno, J. G., Cesaroni, C., Grzesiak, M., Cafaro, M., and De Franceschi, G.
(2019). Improved version of a short-term forecasting model to predict the total electron content over Brazil. In AGU Fall Meeting 2019. AGU.

Damaceno, J. G., Bolmgren, K., Bruno, J., De Franceschi, G., Mitchell, C., and Cafaro, M. (2020). GPS loss of lock statistics over Brazil during the 24th solar cycle. Adv. Space Res., 66(2), 219-225.

https://doi.org/10.1016/j.asr.2020.03.041

De Paula, E. R., Kantor, I. J., Sobral, J. H. A., Takahashi, H., Santana, D. C., Gobbi, D., de Medeiros, A. F., Limiro, L. A. T., Kil, H., ... Taylor, M. J. (2002). Ionospheric irregularity zonal velocities over Cachoeira Paulista. J. Atmos. Sol.-Terr. Phys., 64(12-14), 1511-1516. https://doi.org/10.1016/S13646826(02)00088-3

De Franceschi, G., Spogli, L., Alfonsi, L., Romano, V., Cesaroni, C., and Hunstad, I. (2019). The ionospheric irregularities climatology over Svalbard from solar cycle 23. Sci. Rep., 9(1), 9232. https://doi.org/10.1038/S41598-019-44829-5

Fejer, B. G., Souza, J. R., Santos, A. S., and Costa Pereira, A. E. (2005). Climatology of $F$ region zonal plasma drifts over Jicamarca. J. Geophys. Res.: Space Phys., 110(A12), A12310. https://doi.org/10.1029/2005JA011324

Fejer, B. G. (2011). Low latitude ionospheric electrodynamics. Space Sci. Rev., 158(1), 145-166. https://doi.org/10.1007/s11214-010-9690-7

Fremouw, E. J., Leadabrand, R. L., Livingston, R. C., Cousins, M. D., Rino, C. L., Fair, B. C., and Long, R. A. (1978). Early results from the DNA Wideband satellite experiment-Complex-signal scintillation. Radio Sci., 13(1), 167-187. https://doi.org/10.1029/RS013i001p00167

Ghobadi, H., Spogli, L., Alfonsi, L., Cesaroni, C., Cicone, A., Linty, N., ... Cafaro, M. (2020). Disentangling ionospheric refraction and diffraction effects in GNSS raw phase through fast iterative filtering technique. GPS Solutions, 24(3), $1-13$.

Grzesiak, M., Cesaroni, C., Spogli, L., De Franceschi, G., and Romano, V. (2018). Regional short-term forecasting of ionospheric TEC and scintillation. Radio Sci., 53(10), 1254-1268. https://doi.org/10.1029/2017RS006310

Huang, C. S., and Hairston, M. R. (2015). The postsunset vertical plasma drift and its effects on the generation of equatorial plasma bubbles observed by the C/NOFS satellite. J. Geophys. Res.: Space Phys., 120(3), 2263-2275. https://doi.org/10.1002/2014JA020735

Kil, H., Kintner, P. M., de Paula, E. R., and Kantor, I. J. (2000). Global Positioning System measurements of the ionospheric zonal apparent velocity at Cachoeira Paulista in Brazil. J. Geophys. Res. Space Phys., 105(A3), 5317-5327. https://doi.org/10.1029/1999JA000244

Kintner, P. M., Ledvina, B. M., De Paula, E. R., and Kantor, I. J. (2004). Size, shape, orientation, speed, and duration of GPS equatorial anomaly scintillations. Radio Sci., 39(2), RS2012. https://doi.org/10.1029/2003RS002878

Ledvina, B. M., Kintner, P. M., and De Paula, E. R. (2004). Understanding spacedreceiver zonal velocity estimation. J. Geophys. Res. Space Phys., 109(A10), A10306. https://doi.org/10.1029/2004JA010489

Li, G. Z., Ning, B. Q., Otsuka, Y., Abdu, M. A., Abadi, P., Liu, Z. Z., Spogli, L., and Wan, W. X. (2020). Challenges to equatorial plasma bubble and ionospheric scintillation short-term forecasting and future aspects in east and southeast Asia. Surv. Geophys., 42, 201-238. https://doi.org/10.1007/s10712-02009613-5

Linty, N., Farasin, A., Favenza, A., and Dovis, F. (2018). Detection of GNSS ionospheric scintillations based on machine learning decision tree. IEEE Trans. Aerosp. Electron. Syst., 55(1), 303-317. https://doi.org/10.1109/TAES.2018.2850385

Morton, Y. J., Yang, Z., Breitsch, B., Bourne, H., and Rino, C. (2020). Ionospheric effects, monitoring, and mitigation techniques. In Y. T. Jade Morton, et al. (Eds.), Position, Navigation, and Timing Technologies in the 21st Century: Integrated Satellite Navigation, Sensor Systems, and Civil Applications (pp. 879-937). IEEE.

Muella, M. T. A. H., de Paula, E. R., Kantor, I. J., Batista, I. S., Sobral, J. H. A., Abdu, M. A., Kintner, P. M., Groves, K., M., and Smorigo, P. F. (2008). GPS L-band scintillations and ionospheric irregularity zonal drifts inferred at equatorial and low-latitude regions. J. Atmos. Sol.-Terr. Phys., 70(10), 1261-1272. https://doi.org/10.1016/j.jastp.2008.03.013

Muella, M. T. A. H., de Paula, E. R., Kantor, I. J., Rezende, L. F. C., and Smorigo, P. F. (2009). Occurrence and zonal drifts of small-scale ionospheric irregularities 
over an equatorial station during solar maximum-Magnetic quiet and disturbed conditions. Adv. Space Res., 43(12), 1957-1973.

https://doi.org/10.1016/j.asr.2009.03.017

Muella, M. T. A. H., de Paula, E. R., and Monteiro, A. A. (2013). lonospheric scintillation and dynamics of fresnel-scale irregularities in the inner region of the equatorial ionization anomaly. Surv. Geophys., 34(2), 233-251. https://doi.org/10.1007/s10712-012-9212-0

Muella, M. T. A. H., de Paula, E. R., and Jonah, O. F. (2014). GPS L1-frequency observations of equatorial scintillations and irregularity zonal velocities. Surv. Geophys., 35(2), 335-357. https://doi.org/10.1007/s10712-013-9252-0

Muella, M. T. A. H., Duarte-Silva, M. H., Moraes, A. O., de Paula, E. R., de Rezende, L. F. C., Alfonsi, L., and Affonso, B. J. (2017). Climatology and modeling of ionospheric scintillations and irregularity zonal drifts at the equatorial anomaly crest region. Ann. Geophys., 35(6), 1201-1218. https://doi.org/10.5194/angeo-35-1201-2017

Olla, A., Abadi, P., and Srigutomo, W. (2020). Investigation of the latitudinal occurrence rate of ionospheric plasma bubble in case of strong and weak pre-reversal enhancement in Southeast Asia. J. Phys.: Conf. Ser., 1523, 012024. https://doi.org/10.1088/1742-6596/1523/1/012024

Otsuka, Y., Shiokawa, K., and Ogawa, T. (2006). Equatorial ionospheric scintillations and zonal irregularity drifts observed with closely-spaced GPS receivers in Indonesia. J. Meteor. Soc. Japan, 84A, 343-351. https://doi.org/10.2151/jmsj.84A.343

Otsuka, Y. (2018). Review of the generation mechanisms of post-midnight irregularities in the equatorial and low-latitude ionosphere. Prog. Earth Planet. Sci., 5(1), 57. https://doi.org/10.1186/s40645-018-0212-7

Park, J., Sreeja, V., Aquino, M., Cesaroni, C., Spogli, L., Dodson, A., and De Franceschi, G. (2016). Performance of ionospheric maps in support of long baseline GNSS kinematic positioning at low latitudes. Radio Sci., 51(5), 429-442. https://doi.org/10.1002/2015RS005933

Reinisch, B. W., and Galkin, I. A. (2011). Global lonospheric Radio Observatory (GIRO). Earth, Planets Space, 63(4), 377-381.

https://doi.org/10.5047/EPS.2011.03.001

Saito, S., Maruyama, T., Ishii, M., Kubota, M., Ma, G. Y., Chen, Y. H., Li, J. H., Ha Duyen, C., and Le Truong, T. (2008). Observations of small-to large-scale ionospheric irregularities associated with plasma bubbles with a transequatorial HF propagation experiment and spaced GPS receivers. J. Geophys. Res.: Space Phys., 113(A12), A12313. https://doi.org/10.1029/2008JA013149

Sobral, J. H. A., Abdu, M. A., Pedersen, T. R., Castilho, V. M., Arruda, D. C. S., Muella, M. T. A. H., Batista, I. S., Mascarenhas, M., de Paula, E. R., ... Bertoni, F. C. P. (2009). lonospheric zonal velocities at conjugate points over Brazil during the COPEX campaign: Experimental observations and theoretical validations. J. Geophys. Res.: Space Phys., 114(A4), A04309. https://doi.org/10.1029/2008JA013896

Spogli, L., Alfonsi, L., Cilliers, P. J., Correia, E., De Franceschi, G., Mitchell, C. N., Romano, V., Kinrade, J., and Cabrera, M. A. (2013a). GPS scintillations and total electron content climatology in the southern low, middle and high latitude regions. Ann. Geophys., 56(2). https://doi.org/10.4401/ag-6240

Spogli, L., Alfonsi, L., Romano, V., De Franceschi, G., Joao Francisco, G. M., Shimabukuro, M. H., Bougard, B., and Aquino, M. (2013b). Assessing the GNSS scintillation climate over Brazil under increasing solar activity. J. Atmos. Sol.-Terr. Phys., 105-106, 199-206.

https://doi.org/10.1016/j.jastp.2013.10.003

Spogli, L., Sabbagh, D., Regi, M., Cesaroni, C., Perrone, L., Alfonsi, L., Di Mauro, D., Lepidi, S., Campuzano, S. A., ... Ippolito, A. (2021). lonospheric response over Brazil to the August 2018 geomagnetic storm as probed by CSES-01 and Swarm satellites and by local ground-based observations. J. Geophys. Res.: Space Phys., 126, e2020JA028368. https://doi.org/10.1029/2020JA028368

Sreeja, V., Aquino, M., and Elmas, Z. G. (2011). Impact of ionospheric scintillation on GNSS receiver tracking performance over Latin America: Introducing the concept of tracking jitter variance maps. Space Wea., 9(10), S10002. https://doi.org/10.1029/2011Sw000707

Sultan, P. J. (1996). Linear theory and modeling of the Rayleigh-Taylor instability leading to the occurrence of equatorial spread F. J. Geophys. Res.: Space Phsy., 101(A12), 26875-26891. https://doi.org/10.1029/96JA00682

Thébault, E., Finlay, C. C., Beggan, C. D., Alken, P., Aubert, J., Barrois, O., Bertrand, F., Bondar, T., Boness, A., ... Zvereva, T. (2015). International geomagnetic reference field: the 12th generation. Earth, Planets Space, 67(1), 79. https://doi.org/10.1186/S40623-015-0228-9

Tornatore, V., Cesaroni, C., Pezzopane, M., Alizadeh, M. M., and Schuh, H. (2021). Performance evaluation of VTEC GIMs for regional applications during different solar activity periods, using RING TEC values. Remote Sens., 13(8), 1470. https://doi.org/10.3390/rs13081470

Van Dierendonck, A. J., Klobuchar, J., and Hua, Q. (1993). lonospheric scintillation monitoring using commercial single frequency $\mathrm{C} / \mathrm{A}$ code receivers. In Proceedings of the 6th International Technical Meeting of the Satellite Division of the Institute of Navigation (pp. 1333-1342). Salt Lake City: ION.

Veettil, S. V., Aquino, M., Marques, H. A., and Moraes, A. (2020). Mitigation of ionospheric scintillation effects on GNSS precise point positioning (PPP) at low latitudes. J. Geod., 94(2), 15. https://doi.org/10.1007/s00190-020-01345z

Watson, D. (1999). The natural neighbor series manuals and source codes. Comput. Geosci., 25(4), 463-466. https://doi.org/10.1016/S00983004(98)00150-2

Woodman, R. F., and La Hoz, C. (1976). Radar observations of $F$ region equatorial irregularities. J. Geophys. Res., 81(31), 5447-5466. https://doi.org/10.1029/JA081i031p05447

Yeh, K. C., and Liu, C. H. (1982). Radio wave scintillations in the ionosphere. Proc. IEEE, 70(4), 324-360. https://doi.org/10.1109/PROC.1982.12313

Yokoyama, T., Shinagawa, H., and Jin, H. (2014). Nonlinear growth, bifurcation, and pinching of equatorial plasma bubble simulated by three-dimensional high-resolution bubble model. J. Geophys. Res.: Space Phys., 119(12), 10474-10482. https://doi.org/10.1002/2014JA020708 